\title{
The Patterns of Vowel Insertion in Korean Speakers' Production of English $\mathbf{C}+/ \mathbf{l} /$ and $\mathrm{C}+/ \mathbf{r} /$ Clusters
}

\author{
Kang, Seo-Yoon 1 )
}

\begin{abstract}
This study examines Korean speakers' production of English consonant clusters, focusing on vowel insertion. An acoustic analysis along with a statistical test was carried out to see what factors are involved in this production. The following factors were considered in the present study: phonetic properties, L1 transfer, and cluster types. Specifically, liquid types were considered to see if they cause any difference depending on $\mathrm{C}+/ \mathrm{l} /$ or $\mathrm{C}+/ \mathrm{r} /$ clusters in the onset in terms of vowel insertion patterns. That is, it was examined which Korean speakers produce better, $\mathrm{C}+/ \mathrm{l} /$ or $\mathrm{C}+/ \mathrm{r} /$ clusters. Interestingly, the result of the present experiment shows that the correct answer percent was higher in the $\mathrm{C}+\mathrm{r} /$ onset clusters than $\mathrm{C}+/ \mathrm{l} /$ onset clusters unlike Eckman's (1977) Marked Differential Hypothesis. In other words, the occurrence of the vowel insertion in C+/1/ clusters is higher than $\mathrm{C}+/ \mathrm{r} /$ onset clusters. This may be attributed to $\mathrm{L} 1$ transfer. Furthermore, in the present study, three patterns of vowel insertion in the $\mathrm{C}+/ \mathrm{l} /$ clusters were identified by implementing an acoustic analysis based on vowel duration and formant: a) vowel insertion with gemination, b) phonological epenthesis, and c) phonetic intrusion. However, phonetic intrusion mainly occurred in the $\mathrm{C}+\mathrm{r} /$ clusters. Data were collected from 54 Korean speakers to see what factors are involved in vowel insertion patterns in the production of English consonant clusters. This study provides evidence for L1 transfer, the duration effect of $/ 1 /$ in a different context, and three kinds of vowel insertion patterns in conjunction with gestural coordination by age groups.
\end{abstract}

Key words: L1 transfer, duration, formant, vowel insertion with gemination, phonological epenthesis, phonetic intrusion, gestural constraint

\section{Introduction}

Vowel insertion generally occurs by the syllable structure difference between the target language (L2) and the native language (L1). As Korean, characterized as a $\mathrm{C}(\mathrm{G}) \mathrm{VC}$ language, is a relatively simple compared with English in its syllable structure, vowel insertion is generally motivated. Thus, it has been argued that L1 transfer is the most prominent source of syllable structure errors that Korean speakers of English make. Much research on the production of English consonant clusters by Korean speakers is directed towards formulating phonological

1) Kyung Hee University, sjkang620@naver.com

Received: November 6, 2012

Revised: December 4, 2012

Accepted: December 17, 2012 or P-map principles ${ }^{2}$ ) regarding vowel insertion patterns.

The present study, however, attempts to explore the possibility of accounting for vowel insertion patterns by implementing an acoustic analysis based on duration and formant in conjunction with the concept of gestural constraint.3)

Although there have been numerous studies on vowel insertion in the production of English consonant clusters, I will briefly review the accounts relevant to the present study as following. Broselow \& Park's (1995) mora-based analysis explains the vowel tenseness effect as a way to preserve one of the two morae of a tense vowel in order to account for vowel insertion. This account, however, does not provide a consistent

2) According to Steriade (2001b: 14), the P-map is a set of statements about perceived distinctiveness differences between different contrasts in various contexts.

3) This gestural account is based on articulatory phonology. 
explanation for vowel epenthesis after stops following a short or diphthong vowel as rightfully pointed out by Kang (2003:243). Kang (2003) confirmed vowel insertion patterns as following: vowel insertion is more likely to occur after tense vowels, voiced consonants and coronal consonants. She also argues that vowel insertion is motivated to improve the perceptual similarity between the English input and the Korean output since Korean stop-plus-inserted vowel [i] is acoustically similar to the corresponding English release stop. This explanation, however, lacks a uniform account for vowel epenthesis since she claims that vowel epenthesis results from three different factors: phonetic, phonological, and morphophonemic constraints in Korean. In addition, vowel insertion after word-final postvocalic stops has not been successfully accounted for by Kang's (2003) study.

Following Steriade (2001b:14), Kwon (2005) provides evidence that the P-map is responsible for the pattern of vowel insertion in Korean speakers' production of English consonant clusters. In her study, she presents two proposals to account for the attested pattern of vowel insertion. First, following Cote (2000), she proposes that the likelihood of vowel insertion in consonant clusters correlates with perceptual salience of a segment in consonant. The weaker the perceptual cue of a segment, the more likely it is to be modified. Second, she claims that the second language learners are guided by the P-map when faced with L2 phonotactic constraints that are not part of their native languages. This P-map knowledge leads L2 learners to choose the output form with relatively minimal modification of the input in terms of perceptual similarity. That is, L2 speakers prefer, as a solution, "the least distinctive contrast whose modification resolves the violation. The validity of this P-map principle is also tested in $\mathrm{L} 2$ acquisition of English consonant cluster by Cho \& Lee (2005).

Similarly, Fan's (2004) study on Mandarin Chinese speakers' acquisition of coda clusters demonstrated a good example that the P-map knowledge holds true in L2 phonology. Fan (2004) proposed that the preference of a schwa as an insertion vowel is related to phonetic feature of a schwa since schwa is the shortest vowel in terms of duration and lacks invariant articulatory properties. Accordingly, Fan (2004) proposed that schwa insertion in consonant clusters is perceptually least obtrusive. However, Fan's (2004) study has a limitation in that it is difficult to account for the difference between phonological epenthesis and phonetic intrusion such as schwa insertion. That is, the preference of a schwa as an insertion vowel proposed by
Fan (2004) is not applied to phonological epenthesis, which employs an insertion vowel different from a schwa4). Also, the difference between vowel insertion patterns depending on the kind of liquids in $\mathrm{C}+/ \mathrm{l} /$ and $\mathrm{C}+/ \mathrm{r} /$ clusters is not considered.

Yoo (2004) investigated the influence of markedness in the interlanguage of Korean children in the consonant cluster acquisition, providing additional evidence for the privileged status of onset. Oh \& Kim (2006) claims that vowel epenthesis occurs after a postvocalic word-final stop if the pre-final vowel is long. This phonetic duration based analysis makes crucial reference to subphonemic vowel duration in post-vocalic coda position. Unlike P-map account, Shibuya (2005)5) presented an acoustic and articulatory account within Articulatory Phonology (Browman \& Goldstein, 1986), argued that both phonetics (in the case of the complex coordination of gestural movement of articulators necessary for realization of consonant clusters) and phonology are involved in the Japanese speakers' realization of consonant clusters.

According to Yoo (2009), Korean speakers as well as English speakers tend to geminate intervocallic $/ 1 /$ than $/ 1 /$ in a sequence of consonant and $/ 1 /$. She also states that English speakers do not use gemination as much as Korean speakers due to No-gem constraint in English. However, she does neither account for the duration effect of $/ 1 /$ in a different context accurately, nor does deal with consonant $+/ \mathrm{r} /$ clusters.

To sum up, findings of the previous studies are quite different depending on studies, which may be due to stimuli and subjects themselves. Also, Korean speakers' vowel insertion variation through acoustic analysis in terms of duration is not reflected in previous studies. Moreover, few studies were investigated with regard to age-dependence difference in terms of vowel insertion patterns.

Thus, in the present study, three kinds of vowel insertion patterns related to liquid cluster types will be tested by implementing an acoustic analysis: phonetic intrusion, vowel insertion with gemination and phonological epenthesis.6) I will

4) The inserted vowel in phonetic intrusion and vowel insertion with gemination is regarded as a schwa among three kinds of vowel insertion patterns assumed in this study.

5) The present study is similar to Shibuya (2005) in that it argues that both phonetics (in the case of the complex coordination of gestural movement of articulators necessary for realization of consonant clusters) and phonology are involved in the Japanese speakers' realization of consonant clusters.

6) According to Levin (1987), there are two kinds of vowel intrusion processes: epenthesis and excrescence. Similarly, Shibuya (2005) also divided vowel insertion into two parts. 
also try to test the validity of the assumption that vowel insertion patterns can be classified into three parts based on the duration of the inserted vowel, of $/ 1 /$ in a different syllabic position and formant.

This study is different from previous studies in some respects. First, this study examines duration effect of vowel insertion patterns by looking at data from acoustic analysis in conjunction with gestural coordination. Second, age-related differences regarding vowel insertion patterns in the production of English consonant clusters are also investigated. Third, Liquid types will also be considered to see whether they cause any difference depending on $\mathrm{C}+/ \mathrm{l} / \mathrm{vs}$. $\mathrm{C}+/ \mathrm{r} /$ clusters in the onset. Eckman's (1977) Markedness Differential Hypothesis is related to this question, which claims that the different areas of the target language would be those that are both different from and relatively more marked than the ones in L1.

The primary goal of the present study is to explore the possibility of accounting for the vowel insertion patterns depending on liquid cluster types and age by implementing acoustic analysis and to examine what kinds of factors are involved in vowel insertion. To achieve this goal, the following research questions will be investigated in this study: 1) What factors are influential for vowel insertion patterns of Korean speakers in $\mathrm{C}+/ \mathrm{l} /$ and $\mathrm{C}+/ \mathrm{l} /$ clusters? 2) What is the difference between $\mathrm{C}+/ \mathrm{l} /$ and $\mathrm{C}+/ \mathrm{r} /$ onset clusters regarding the frequency of vowel insertion and vowel insertion patterns, focusing on durational effect?

This study seeks to provide answers to these questions by looking at data from Korean speakers learning English through acoustic analysis.

\section{Linguistic background}

\subsection{Syllable structure constraint in Korean}

Korean and English are different in their syllable structure. Korean has a relatively simple syllable structure $\mathrm{C}(\mathrm{G}) \mathrm{VC}$, compared with English syllable structure. Only a single consonant in Korean syllable structure is allowed in both onsets and codas and nucleus permits a vowel or a diphthong. Underlyingly, however, two consonants are allowed in Korean codas.

In addition to this syllable structure, I also employs CVQ syllable structure ${ }^{7)}$, which represents a syllable that is closed by

7) For accounting for vowel insertion with [1]-gemination, CVQ syllable structure is needed (Lee, 2005). However, for the first part of geminate consonant to explain vowel insertion with [1]-gemination. Here, please note that Korean is another language in which CVQ syllable behave as bimoraic, whereas other closed syllables behave as monomoraic (Lee, 2005). Let us now turn to cluster phonotactics in Korean.

$\begin{array}{ccc}\text { (1) Korean Cluster Constraint: } & { }^{*} \mathrm{C} & \mathrm{C}(\mathrm{Ahn}, 2009) \\ \text { (Syllable-internal) } & \mid & \mid \\ & {[]} & {[\mathrm{]}}\end{array}$

As seen above, Korean does not allow complex onsets and codas. Korean cluster constraint precludes clustering of consonants whose association with phonological features is independent of one another, but it does not block $\mathrm{CC}$ arrangements which share phonological feature structure underlyingly. Thus, Korean is a language that does not allow complex onsets or codas in a syllable internal.

\subsection{Gestural coordination ${ }^{8)}$}

Browman \& Goldstein (1986, 1990, 1992a, 1992b) proposed an approach to phonological representation based on the idea of gestural coordination, called Articulatory Phonology.9) According to this theory, consonants and vowels are mutually coordinated. If the amount of overlap between two consonants in a cluster is not enough, the resulting production of that particular gestural organization leads to the perception that a vowel has been inserted, thereby resulting in producing a vowel-like transition.

Articulatory Phonology helps us understand the gradient nature of phonetics and categorical nature of phonology since it is a theory which aims to integrate phonetics and phonology by defining the basic unit of phonological contrasts as the articulatory gesture. Thus, in the framework of Articulatory Phonology, phonological and phonetic representations are considered to be the same. According to Levin (1987), there are two kinds of vowel intrusion processes: epenthesis (phonological insertion) and excrescence (phonetic intrusion). Phonological insertion refers to vowels that are phonologically inserted as a result of repair strategy for English consonant clusters. On the

gemination without vowel insertion, CVQ syllable structure can be problematic since $\mathrm{V}$ is missing.

8) This gestural coordination is regarded as the same as coarticulation in this study since both gestural coordination and coarticulation are related to gestural overlapping.

9) According to articulatory phonology, both vowel insertion and deletion can also be accounted for depending on gestural movement according to time interval. 
other hand, phonetic intrusion refers to vowel-like transition that is no phonological representation. Therefore, phonetic intrusion is expected to show gradient duration as well as varying vowel quality depending on the surrounding consonants. Because of these properties, phonetic intrusion has nature similar to schwa-like transition. Specifically, this kind of schwa is called targetless schwa, as it has no specifed tongue position (Browman \& Goldstein, 1992a). Acoustically, this kind of schwa is generally very short in duration ${ }^{10)}$ and shows characteristics such as durational, vowel quality variance.

\section{3 [1]-gemination in consonant cluster position}

It has been argued that the high percent of correct production and perception of liquids at the initial consonant cluster position is attributed to influences of Korean phonology (Jun, 2005). This may be because the sound structure of the English /1/ in consonant cluster position is considered to be similar to the Korean geminate [11]. This divergent process such as [11] derived from $/ 1 /$ can be difficult to explain if we judge from just Korean phonemic status where there is only a single liquid phoneme. In Korean phonology, geminate [11] and flap are distinct in the intervocalic position (Lee, 2005). There are more studies on the liquid gemination (Kenstowicz, 2005; Oh, 2005). But, their study are a little different in that they use different constraints. For instance, Oh (2005) assumes the perceptual similarity whereas Lee (2005) provides OT accounts using moraic constraint. Now, let us consider [1]-gemination occurred in producing English consonant clusters by Korean speakers.

According to Jun (2005), she states that the first half articulation of $/ 1 /$ occurred in producing English consonant clusters like 'play' corresponds to the first half [1] of Korean geminate [11]. And the latter half articulation corresponds to the latter half [1] of Korean geminate [11]. Thus, we can see that English segment $/ 1 /$ corresponds to Korean [11] as 1 to 2 . That is, the segment $/ 1 /$ in the target language is not the smallest unit that cannot be divided. In generative phonology, a segment can be divided as distinctive features (Jun, 2005). However, the important aspect assumed in this study is that the smallest unit that can be divided is not distinctive features but articulation gestures. In this respect, gestural phonology, which states that segments consist of articulatory gestures, can better account for [1]-gemination in Korean phonology than generative phonology.

10) In the present study, an acoustic analysis reveals that the mean duration of this kind of schwa is approximately $0.05(\mathrm{~s})$, in spite of durational variation.
Furthermore, when it comes to ambi-syllabification of English segment $/ 1 /$ in cluster position, it is said that the first half articulation gesture belongs to the syllable-initial position, and the latter half articulation gesture belongs to the syllable-final position. However, regarding ambi-syllabification, it has been assumed that segments are not divided, and they belong to ambi-syllables at the same time. Hence, segmental syllabification structure of $/ 1 /$ based on articulation gestures can show a new approach to ambi-syllabification theory (Jun, 2005). Now, let us look at the following figure as in (2).

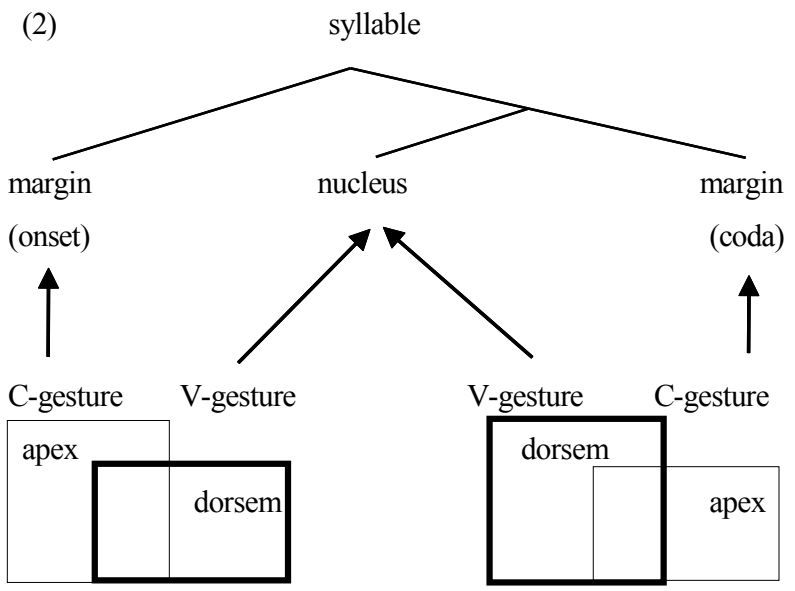

Schematic view of Sproat and Fujimura's (1993) gestural account of lateral in English

Consonantal gestures are attracted to syllable margins; vocalic gestures are attracted to syllable nuclei, as can be shown in (2). Given this, it seems that [1]-gemination occurred in producing English consonant clusters is related to this gestural account of lateral since vowel insertion with gemination involves a situation where the inserted vowel and the first half lateral sound are coordinated. In addition to this, this gestural account may support the fact that a single input $/ 1 /$ is divided and mapped onto two modified outputs, [11]. This can also be schematized as in (3). Modified English Input $/ 1 /$ grammar (transfer) $\longrightarrow \underset{\substack{\text { Modified } \\ \text { Output2[1] }}}{\text { Output1[1] }}$

As seen above, a segment of a target sound does not correspond to one output. That is, as mentioned above, English 
segment $/ 1 /$ corresponds to Korean [11] as 1 to 2 . At this point, a question can be raised as to how we can split one segment into two parts, In articulatory (gestural) phonology, as mentioned above, it is said that a segment can be divided as articulatory gestures, which are considered as a basic unit of phonological representation. Thus, gestural phonology can better account for vowel insertion with [1]-gemination than other linguistic framework due to the gestural aspect that segment consists of articulation gestures that can be divided into two articulatory gestures.

\section{Production Experiment}

Many experiments on vowel insertion have been conducted by researchers, however, the findings are quite different. Accordingly, in this section, I will try to test the validity of the results of previous studies by conducting acoustic analysis, specifically focusing on the variation of vowel insertion patterns in producing English consonant clusters by Korean speakers. By conducting this acoustic analysis, it is also expected to achieve the goal of the study by answering the questions presented in the previous section. In order to find the answers, duration and formant frequencies of the inserted vowel as well as the ratio of vowel insertion depending on cluster types will be measured.

\subsection{Experimental design}

\subsubsection{Subjects}

The 54 Korean learners of English participated in this production experiment. They were recruited from the Seoul-Kyeonggi Metropolitan area. The subjects are composed of three age groups ranging from Korean elementary school students to middle school students including high school students. Each group consists of 18 speakers of English.

One group of participants consisted of Korean children who attend elementary school. The second group consisted of Korean learners who are at the middle school and the third group consisted of high school students. All subjects had lived in Korea, studied English for more than 3 years. All students were intermediate or advanced English learners collected on the basis of English-related course records $70-80 \%$ out of $100 \%{ }^{11)}$

11) Their proficiency levels of English were also judged by a native speaker who majored in TESOL since most of the participants do not have recent TOEFL, TOEIC grades.

\subsubsection{Stimuli}

In total, English words (1081 target words12)) were used. The target words tested in the present study were elicited from Yoo (2004) and Cho \& Lee (2005). The stimulus items with three-member consonant clusters were excluded in this experiment. The following table shows attested words used in this experiment with regard to two-member onsets including liquids (CC).

Table 1. Attested words in word initial clusters

\begin{tabular}{|l|l|}
\hline \multirow{2}{*}{ Obs+liquid } & $\begin{array}{l}\text { obs }+/ 1 /(\text { blue, glove, cloudy, play, glass, please, } \\
\text { flower, flat, slot) }\end{array}$ \\
\cline { 2 - 2 } & $\begin{array}{l}\text { obs }+/ \mathrm{r} /(\text { breakfast, pray, try, grass, friend, } \\
\text { green, crime, dragon, pretty) }\end{array}$ \\
\hline $\mathrm{C}+/ \mathrm{r} /$ & through, shrimp, freeze \\
\hline
\end{tabular}

\subsubsection{Procedure}

The participants were asked to read word lists, which appeared one by one with a pause in a quiet room. Each participant read all the items in individually randomized order. Some practice tests were provided before the main recording session. Subjects were told to look it over to check if there were unfamiliar expressions. Their readings were recorded using Praat program (version 4.4.20). Korean speakers' vowel insertion patterns according to cluster types were examined by three trained linguists. Each documented vowel insertion was noted and agreed upon by two linguists13) based on the waveforms and spectrograms as well as the perception of the vowel sounds. Duration and formant values of the inserted vowel were also measured by using the Praat program to examine the vowel quality of the inserted vowel and the nature of $/ 1 /$.

The results of the test were encoded on the statistics program for statistical analysis. the occurrence of the vowel insertion was coded as 1 and the absence of the vowel insertion as 0 and the other factors were also specified. The statistical analysis was processed to see how the age groups will be different, see what the difference is between $\mathrm{C}+/ \mathrm{l} /$ onset clusters and $\mathrm{C}+\mathrm{r} /$ onset clusters in the patterns of vowel insertion

12) In the case of elementary school students, some of total attested words are missing since the number of sample items used in this experiment is less than that of other two groups. 13) One linguist is a native speaker of English, the other linguist is a Korean graduate school student who is majoring in phonetics. 
3.2 Acoustic analysis

\subsubsection{Presence/absence of inserted vowels}

In the present study, whether there are inserted vowels or not is tested in order to investigate Korean speakers' production of English consonant clusters. The waveforms and spectrograms of all tokens were examined for the presence or absence of the inserted vowel. An insertion vowel was judged to be present if three of the following were observed: (1) voicing in the waveform; (2) a visible formant structure, especially F1 and F2 in the spectrogram; (3) an increase in amplitude and (4) vowel periodic patterns in the waveform.

Specifically, the insertion of a vowel was judged to be present based on the appearance of clear formants and the energy of the waveform. Thus, I first looked at the formants to examine if there is an inserted vowel. And if they are clear enough to be identified as an inserted vowel, then I looked at amplitude of the waveform. However, I identified the inserted vowel as a schwa if amplitude is not strong enough to be seen compared to other inserted vowels and the duration of the inserted vowel is relatively short, on the basis of $0.05(\mathrm{~s})$. This basis of duration is a crucial criterion to be identified as phonetic intrusion. This will be discussed further later.

3.2.2 The criteria of segmentation in vowel insertion with gemination

In the present study, acoustic analysis reveals that there are three kinds of vowel insertion patterns in producing English $\mathrm{C}+/ \mathrm{l} /$ and $\mathrm{C}+/ \mathrm{r} /$ clusters: vowel insertion with gemination ${ }^{14)}$, phonological epenthesis, phonetic intrusion. In order to obtain the validity of dividing vowel insertion patterns into three kinds of patterns in the figure depending on duration, formant frequencies, and amplitude, the accurate criteria of the segmentation should be presented. Thus, I will first present the criteria of the segmentation that I labelled in vowel insertion with gemination as following.

Consonant clusters containing lateral $/ 1 /$ like $\mathrm{C}+/ \mathrm{l} / /$ clusters show no stable formant between a consonant before lateral /l/ and lateral $/ 1 /$ sound due to the acoustic characteristics of $/ 1 /$ sound. For this reason, if a spectrogram shows a stable formant before the transition from the [1] sound to the next vowel, I identified this as double appearance of [1], resulting in

14) Vowel insertion with [1]-gemination mainly occurs in $\mathrm{C}+/ \mathrm{l} /$ clusters, but as for $\mathrm{C}+/ \mathrm{r} /$ clusters, vowel insertion with gemination never occurs except for 'shrimp'. gemination [11]. Also, it is observed that this [1]-gemination occurring in Korean speakers' vowel insertion increases the duration of the segment $/ 1 /$ as $\mathrm{Oh}(2005)$ pointed out 15$)$. Thus, the duration of geminate [11] is another crucial clue to be distinguished from that of a single [1] sound.

In particular, please note that the gemination is divided into two kinds of gemination: gemination with vowel insertion and gemination without vowel insertion. For the former case, gemination with vowel insertion is labeled by distinguishing the inserted vowel from the front [1] of geminate [11] when there is a transition or any change of formant between the preceding consonant of $\mathrm{C}+/ \mathrm{l} /$ clusters and the first half [1] of geminate [11]. Once again, the geminate [11] is divided into the former [1] and the latter [1] as in [1.1] in order to indicate syllable boundary phonologically based on the change of energy in waveform phonetically. For the latter case, on the other hand, I didn't add any additional segmentation to identified as the inserted vowel if there is no change of formants. As a result, only gemination without any kinds of vowel-like transition occurs.

Now, let us look at waveforms and spectrograms of vowel insertion with gemination, as in figure below. The following figure shows waveform and spectrogram of insertion vowel with gemination produced by a Korean high school student. First of all, let us look at waveform and spectrogram of the inserted vowel with [1]-gemination in onset cluster 'blue' as seen below.

a. Spectrogram and waveform of the inserted vowel with gemination

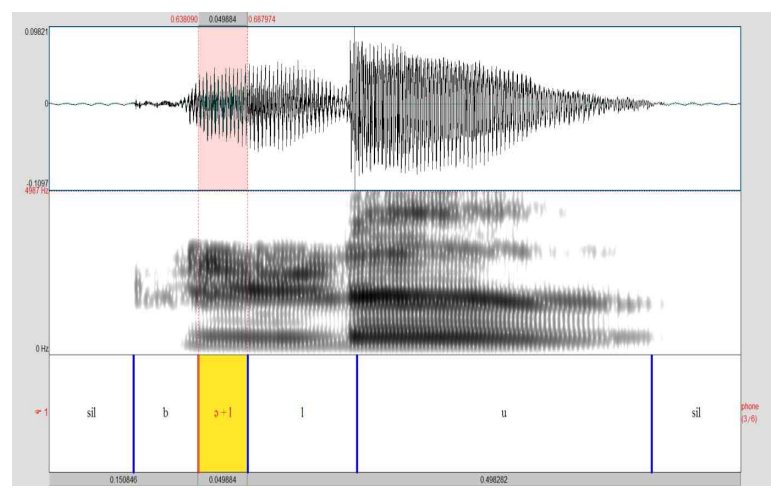

Figure 1. Onset_L_gem_blue_(KJ)

As shown in Figure1, we can find that there occurs vowel insertion with gemination based on the criteria identified. The

15) Oh (2005) proved highly significant correlations between the spelling of English $/ 1 /$ and gemination, in which she assumed perceptual similarity to account for liquid gemination. 
reason why I indicate like $\left.\partial^{+1}\right]_{\sigma}{ }^{16}$ in the figure 1 is that we cannot distinguish the difference between [ə] and [1] in the spectrogram accurately ${ }^{17)}$. This may be because articulation gestures of $2+1] \sigma$ are proceeded simultaneously and in doing so the closing gesture of [1] in cluster position is so closely linked to the proceeding inserted vowel that Korean speakers would associate the first half [1] of two [1.1] with the proceeding inserted vowel, resulting in a situation similar to gestural coordination. Accordingly, I can identify articulation of [ə] and [1] as $2+1]_{\sigma}{ }^{18)}$. In other words, before the articulation gesture of the inserted vowel is completed, the raising gestural articulation of the front [1] is made with the tip of the tongue touching the alveolar so that air passes out at the side of tongue. Here, the reason why I divide the geminate [11] into two parts [1.1] is that waveform as in figure 1 shows the slight change of energy phonetically, and that the geminate can be divided into two [1.1] on the basis of syllable boundary phonologically.

To sum up, two striking findings were observed in vowel insertion with gemination. First, among two [1.1], the first half [1] before syllable boundary is coordinated with the preceding inserted vowel, [ə]. Thus, as we could not find the criterion to distinguish the difference between the length of the inserted vowel and that of the first half [1] sound in the spetrogram. Accordingly, $2+1] \sigma$ observed in $\mathrm{C}+/ \mathrm{l} /$ clusters can be a piece of evidence to support the assumption that gestural constraint can better account for vowel insertion with gemination than the perceptual account. Second, the inserted vowel in vowel insertion with gemination is similar to schwa (or schwa-like transition) due to the very short duration, relatively unclear formant structure, and unspecified tongue position. In addition, we can find that although the duration of [vl] is 0.049 (s), the sum of the two [vll] is $0.16(\mathrm{~s})^{19)}$ as in the table below. Thus, we can confirm that the duration of vowel insertion with gemination is considerably long. But, the frequencies of formant

16) Here, '+' means coordination or coarticulation effects of two gestures. And $\sigma$ indicates syllable boundary.

17) However, we can confirm that $F 2$ value of the inserted vowel [ə] is slightly higher than that of frontal [1] in the spectrogram. This is an important clue to distinguish vowel insertion with gemination from [1]-gemination without vowel insertion, even though only acoustic output cannot capture the process of the movements of articulators accurately.

18) Also, I can account for the difference between vowel insertion with gemination and gemination without vowel insertion [11] by posing this notation $\left.\partial^{+1}\right] \sigma$.

19) As pointed out by (Oh, 2005), the length of geminate [11] is long, compared with single[1], since gemination increases the duration of the segment. structure are a little different from a schwa (F1:500, F2:1500), as seen in the table below.

Table 2. Values of duration of [vll] and formant of the inserted vowel [ə] in 'blue' produced by KJ

\begin{tabular}{|c|c|c|c|}
\hline $\operatorname{dur}(\mathrm{s})^{20)}$ & F0(Hz) & F1(Hz) & F2(Hz) \\
\hline 0.16 & 241 & 489 & 1848 \\
\hline
\end{tabular}

In specific, I can confirm that F2 value of the inserted vowel $(1848 \mathrm{~Hz}),[0]$ is slightly higher than that of [1] in the articulation gestures of $\left.\partial^{+1}\right]_{\sigma}$ in the spectrogram even though they are coordinated. The values of F1, however, shows no significant difference between [ə] and the first half [1]

\subsubsection{The criteria to distinguish phonological epenthesis} from phonetic intrusion

As mentioned in the previous section, the present acoustic analysis reveals that there are three kinds of vowel insertion patterns in producing English consonant clusters: vowel insertion with gemination ${ }^{21)}$, phonological epenthesis, phonetic intrusion. In particular, phonological epenthesis is distinguished from phonetic intrusion on the basis of the longer duration along with relatively clearer formant frequencies and strong amplitude compared with phonetic intrusion. The first question was in section1:What factors are influential for vowel insertion patterns of Korean speakers in $\mathrm{C}+/ \mathrm{l} /$ and $\mathrm{C}+/ \mathrm{l} /$ clusters? To answer this question, we first need to answer the following question.

Do Korean speakers produce a vowel phonologically (phonological epenthesis), phonetically (phonetic intrusion) in their production of consonant clusters? Here, the criteria to distinguish phonological epenthesis from phonetic intrusion ${ }^{22)}$ are: (1) the duration of the inserted vowel; (2) formant structure; (3) the intensity of amplitude. In particular, distinction between phonological epenthesis and phonetic intrusion can be

20) Here, the duration $0.16(\mathrm{~s})$ indicates the duration of $[2+1]$ and [1], as it is hard to distinguish the difference between the inserted vowel and [11] in the spectrogram accurately, but we can distinguish the difference in the change of amplitude in the waveforms phonetically, resulting in syllable boundary as in [1.1] phonologically.

21) Vowel insertion with [1]-gemination mainly occurs in $\mathrm{C}+/ 1 /$ clusters, but as for $\mathrm{C}+/ \mathrm{r} /$ clusters, vowel insertion with gemination never occurs except for 'shrimp'.

22) The differences between a phonetic intrusion and a phonological insertion were also discussed in Levin's (1987) research. but, this study focused on duration, and divided into three parts unlike Levin's (1987) study. 
restated as following: The main differences between phonological and phonetic vowel insertion are the formants and the duration. Firstly, phonological vowel insertion has relatively clearer formants than phonetic intrusion. Also, phonological vowel insertion contains less formant transition than phonetic vowel insertion. Secondly, the duration of phonological vowel insertion is longer than that of phonetic vowel insertion. If the duration of the inserted vowel is longer than $0.05(\mathrm{~s})$, formant structure is clearer, the inserted vowel is judged to be phonological epenthesis. On the other hand, if the duration of the inserted is shorter than $0.05(\mathrm{~s})$, formant structure is less clear relatively, and the amplitude is weak, the inserted vowel is judged to be phonetic intrusion. Now, let us first look at phonological epenthesis in onset 'please' produced by DJ.

b. Spectrogram and waveform of the phonological epenthesis

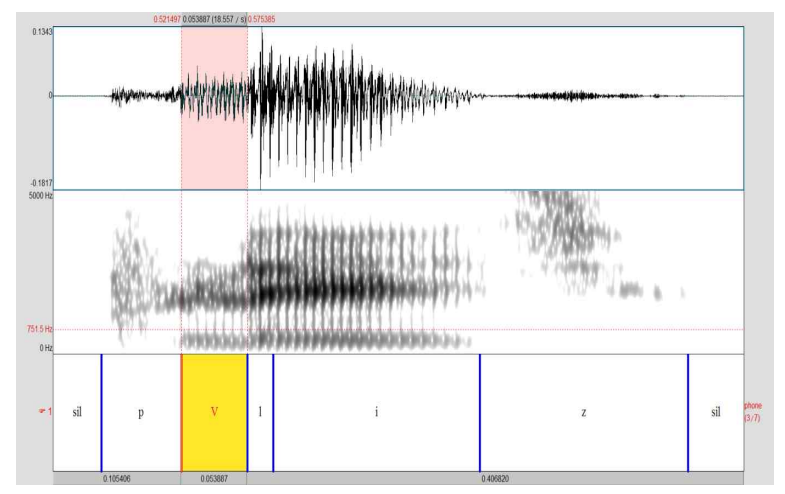

Figure 2. onset_L_pl_please'_DJ

As shown in the figure above, we can find that there occurs vowel insertion without gemination. The duration of the inserted vowel is $0.053(\mathrm{~s})$, and the duration of [vl] is $0.07(\mathrm{~s})$ as seen below, Here, we can see that the duration of $[\mathrm{vl}], 0.07(\mathrm{~s})$ is relatively short compared to the duration of [vll] in vowel insertion with gemination, $0.16(\mathrm{~s})$. Accordingly, we can say that there is durational difference according to vowel insertion patterns. Now, let us look at formant values, as seen below.

Table 3. Values of duration of [vl] and formant of the inserted vowel in 'please' produced by DJ

\begin{tabular}{|c|c|c|c|}
\hline $\left.\operatorname{dur}(\mathrm{s})^{23}\right)$ & $\mathrm{F} 0(\mathrm{~Hz})$ & $\mathrm{F} 1(\mathrm{~Hz})$ & $\mathrm{F} 2(\mathrm{~Hz})$ \\
\hline 0.07 & 138 & 423 & 1685 \\
\hline
\end{tabular}

23) The result on duration may be a little different as the durational distinction attributed to the difference of syllable, voicing, stress, and the place of articulation of the preceding consonant is not considered, although this may affect the duration of [vl] or [vll]. Thus, more attention should be needed.
As is clear from the table above, we can see that the formant values of the inserted vowel in phonological epenthesis are different from those of the vowel insertion with gemination in that the values of F1 and F2 of the inserted vowel as in 'please' are slightly lower than those of F1 and F2 as in 'blue.

At this point, one may question as to why the differences of voicing, the number of syllables, and stress were not considered since these factors may affect the duration of [vl]. However, even though these factors are considered, it is hard to account for the durational difference according to cluster types without dividing the insertion patterns. Thus, in this study, I only focused on the durational difference depending on cluster types and vowel insertion patterns. Now, let us consider phonetic intrusion in $\mathrm{C}+\mathrm{r} / \mathrm{c}$ cluster 'green' produced by DJ. The following figure shows that spectrogram and waveform of the phonetic intrusion. We can observe that the duration of the inserted is considerably short compared with phonological epenthesis.

\section{c. Spectrogram and waveform of the phonetic intrusion}

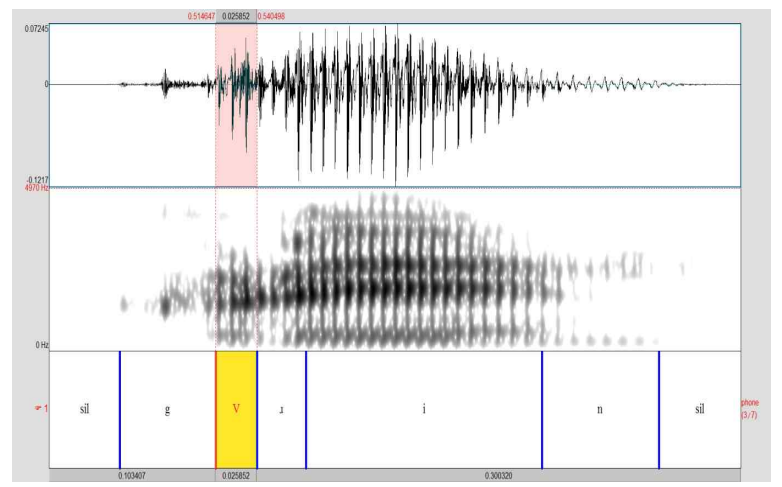

Figure 3. onset_R pn_'green'_DJ

The following table shows the duration and formant value of the inserted vowel in phonetic intrusion. the duration of the inserted vowel is $0.025(\mathrm{~s})$, as in the table below.

Table 4. Values of duration and formant of the inserted vowel[v] in 'green' produced by DJ

\begin{tabular}{|c|c|c|c|}
\hline $\operatorname{Dur}(\mathrm{s})$ & $\mathrm{F} 0(\mathrm{~Hz})$ & $\mathrm{F} 1(\mathrm{~Hz})$ & $\mathrm{F} 2(\mathrm{~Hz})$ \\
\hline 0.025 & 121 & 540 & 1497 \\
\hline
\end{tabular}

As seen above, we can see that the duration of the inserted vowel is relatively short compared with $0.053(\mathrm{~s})$ in phonological epenthesis. We can also confirm that formant values of phonetic intrusion is similar to schwa (F1:500, F2:1500). 
3.3 The overall results of $\mathrm{C}+/ \mathrm{l} /$ clusters vs. $\mathrm{C}+/ \mathrm{r} /$ clusters in the acoustic analysis

As for $\mathrm{C}+/ \mathrm{l} /$ clusters and $\mathrm{C}+/ \mathrm{r} /$ clusters in the onset, we can identify that there occur asymmetries in the number of vowel insertion depending on liquid types of the following consonant in a cluster, that is, $\mathrm{C} 2$. On the other hand, the experimental findings in Kwon's (2005) study demonstrate that vowel insertion is more likely to occur when $\mathrm{Cl}$ is stop than a strident or a sonorant and when $\mathrm{Cl}$ is a voiced stop than a voiceless stop. She also asserted that the P-map (Steriade, 2001a, 2001b) is responsible for the pattern of vowel insertion in Korean speakers' production of English consonant clusters.

Unlike Kwon (2005), I claim that the liquid types of C2 as well as $\mathrm{C} 1$ in a cluster may affect the vowel insertion patterns. This is because $\mathrm{C}+/ \mathrm{l} /$ clusters in the onset is more likely to experience vowel insertion with gemination, while $\mathrm{C}+/ \mathrm{r} /$ clusters mainly undergo the phonetic intrusion. Therefore, the difference of vowel insertion patterns as well as the number of vowel insertion between $\mathrm{C}+/ \mathrm{l} /$ clusters and $\mathrm{C}+/ \mathrm{r} /$ clusters can support the assumption that the liquid types of $\mathrm{C} 2$ in a cluster can also affect vowel insertion patterns. In other words, vowel insertion variation can also be motivated depending on the phonetic characteristics of the following segment, C2. This asymmetry between $\mathrm{C}+/ \mathrm{l} /$ clusters and $\mathrm{C}+/ \mathrm{r} /$ clusters can be shown in the table below. Let us look at the ratio of vowel insertion in $\mathrm{C}+/ \mathrm{l}$, and $\mathrm{C}+/ \mathrm{r} /$ clusters in the following table.

Table 5. Ratio of vowel insertion in the onset 24)

\begin{tabular}{|l|c|c|}
\hline Total of onset tokens & \multicolumn{2}{|c|}{ Number of vowel insertion } \\
\cline { 2 - 3 }$: 1081^{25)}(467+614)$ & $\mathrm{C}+/ 1 /$ (335:tokens) & $\mathrm{C}+/ \mathrm{r} /(71:$ tokens $)$ \\
\hline Vowel insertion ratio & $71.73 \%$ & $11.56 \%$ \\
\hline
\end{tabular}

As seen above, the occurrence ratio of vowel insertion in $\mathrm{C}+/ 1$ clusters is much higher than that of $\mathrm{C}+/ \mathrm{r} / \mathrm{clusters}$. The result of this experiment is striking in two respects. One is that the ratio of vowel insertion in $\mathrm{C}+/ 1$ clusters is unexpectedly too high compared with $\mathrm{C}+/ \mathrm{r} /$ clusters. The other is that the liquid types of $\mathrm{C} 2$ as well as $\mathrm{C} 1$ affected the result of the vowel insertion patterns considerably. Thus, this result is a strong evidence to support the assumption that liquid types of $\mathrm{C} 2$ may affect the vowel insertion patterns as already mentioned above.

In fact, it has been generally reported that there occur

24) Table on the difference of the ratio of vowel insertion depending on age groups was not presented since there were no big differences among age groups.

25) Here, I excluded the number of speech error occurred in the middle of experiment among the total number of tokens. asymmetries in the number of vowel insertion depending on the type of $\mathrm{C} 1$ consonant in a cluster. However, as seen above, the asymmetry in the mean percentage of vowel insertion also occurs depending on the type of $\mathrm{C} 2$ consonant in a cluster.

At this point, one may question as to why the asymmetry occurs depending on liquid types of $\mathrm{C} 2$ consonant in a cluster. This may be related to L1 transfer regarding [1]-gemination in intervocalic position. As for $\mathrm{C}+/ \mathrm{l} /$ clusters, it has been argued that L1 transfer is the most prominent source of syllable structure errors. To answer this question, let us first compare English speakers' productions (Yoo, 2009) with those of Korean speakers in the current study. Since Korean does not allow syllable initial $\mathrm{CC}$, [i] is inserted between the consonants, resulting in $\mathrm{CiC}$. At the same time [1]-gemination is expected since English /1/ is best represented as Korean geminate [11] in intervocalic position. Moreover, when Korean speakers hear English $/ 1 /$, they think that the perceptually most similar sound is a geminate [11]. English speakers preferred simple epenthesis for the initial $\mathrm{C}+/ \mathrm{l} /$ clusters, represented global as <gi.lo.bəl $>$. $65 \%$ use only insertion without gemination, whereas $30.5 \%$ of the English speakers apply gemination (Yoo, 2009). On the other hand, Korean speakers in the current experimental study in producing English $\mathrm{C}+/ \mathrm{l} /$ clusters used gemination in $80.34 \%$ of the cases, $15.61 \%$ used only phonological epenthesis. Accordingly, I contend that L1 transfer of [1]-gemination is the most prominent source of vowel insertion patterns in $\mathrm{C}+/ \mathrm{l} /$ clusters. That is, we can say that L1 transfer of Korean phonology affected Korean speakers' vowel insertion patterns rather than markedness. ${ }^{26)}$ Now, let us explore what kind of aspect of gemination affects Korean speakers' vowel insertion patterns. Specifically, I will focus on the duration assumed as a major factor in this study in the following section.

3.4 The duration in vowel insertion with [1]-gemination

As mentioned above, [1]-gemination is related to vowel insertion since English /1/ is best represented as geminate [11] in intervocalic position as in English loanwords in Korean. Similarly, [1]-gemination in the production of English consonant clusters by Korean speakers was observed in second language acquisition. If vowel insertion occurs in $\mathrm{C}+/ \mathrm{l} /$ clusters, [1]-gemination in the intervolic context is always involved. For

26) Unlike the results of the present study, Yoo (2009) reports that Korean speakers even used gemination in $98.9 \%$ of the cases in English loanwords. This may be due to the difference of subjects, and stimuli themselves. 
instance, 'glove' is pronounced as [gil.lo.bə]. Interestingly, it is also observed that this [1]-gemination observed in the Korean speakers' vowel insertion patterns increases the duration of the segment $/ 1 /$. Thus, the duration of a geminate [11] is expected to be longer than that of a single [1], and distinct from [1] in terms of duration, Thus, in the current study, I measured the duration of [vll $]^{27)}$ to test how long geminate is, and compare it with the duration of a single [1] in vowel insertion without gemination in producing English consonant clusters. Yoo's (2009) analysis also deals with vowel insertion with gemination, vowel insertion without gemination. Yoo's (2009) analysis, however, does not deal with the duration of vowel insertion with gemination, phonetic intrusion in the production by L2 speakers. However, in the current study, all of vowel insertion patterns will be treated by dividing into three kinds of patterns. Now, let us first look at the following table. the following table shows the duration of vowel insertion with gemination [v1l] by age groups.

Table 6. The mean duration of the inserted vowel with gemination [vll] in the onset by age groups

\begin{tabular}{|c|c|c|}
\hline ESL & MSL & HSL \\
\hline $0.15(\mathrm{~S})$ & $0.14(\mathrm{~S})$ & $0.11(\mathrm{~S})$ \\
\hline
\end{tabular}

As seen above, interestingly, the results here show that the duration of [vll] is considerably long in all age groups and that the duration of [vll] decreases as the age is older. The total mean value in vowel insertion with gemination is $0.13(\mathrm{~s})$. However, we should also note that there is gemination without vowel insertion. Let us look at the following figure.

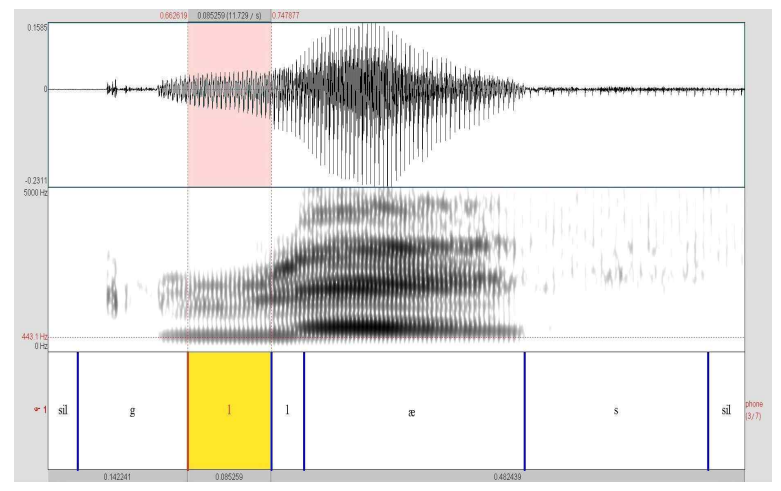

Figure 4. onset_cl_gem_'glass'_JH

As shown in figure 4, when only gemination without vowel

27) The reason why I measured the duration of [vll] is that the distinction between [v] and [1] or [1] and [11] in isolation is not easy to distinguish in the spectrogram. insertion occurs, the duration of the first half [1] of geminate [11] is $0.085(\mathrm{~s})$. In addition, [ə] is missing unlike $\partial+1] \sigma$ in vowel insertion with gemination as in figure 5. Thus, we can conjecture that there is durational variation depending on duration effect of $/ 1 /$ in a different context. Once again, let us look at spectrogram and waveform of vowel insertion with gemination in the following figure produced by YJ.

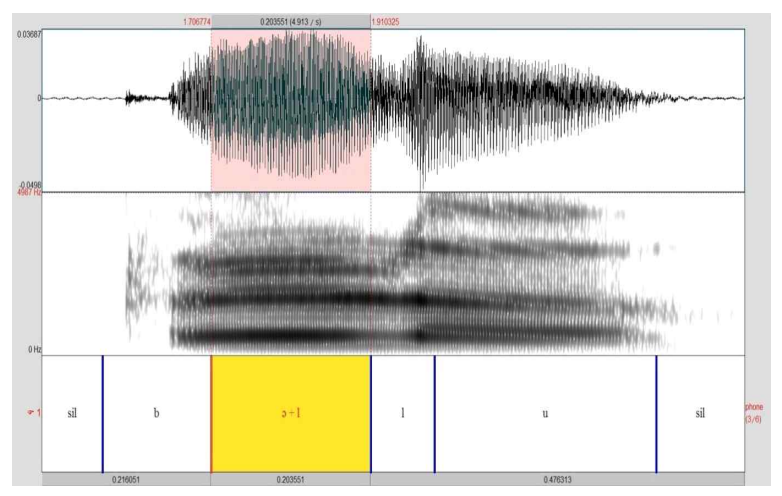

Figure 5. Spetrogram and waveforms in onset L 'blue' gemination $\mathrm{YJ}$

We can see that the duration of $[\mathrm{vl}]$ is $0.2(\mathrm{~s})$, the longest value of all participants ([vll]:0.3(s)). The distinction between the inserted vowel and the first half [1] of two [1.1] in the spectrogram is not clear since they are coordinated, and appear to form one segment in spectrogram ${ }^{28)}$. Thus, I can say that the gestural coordination (or coarticulation ${ }^{29)}$ ) occurs in the production of 'blue' by YJ. As mentioned in 3.2.2, the two [1.1] is divided into the former [1] and the latter [1] in syllable boundary phonologically and can also be divided into two parts by the change of energy in the waveform phonetically. That is, gestural coordination between the inserted vowel and the first half [1] occurs because the gestural movement of the front [1] of [1.1] begins to reach alveolar ridge before the gestural movement of the inserted vowel is completed, as mentioned in 3.2.2.

In sum, we can say that vowel insertion along with coarticulation and gemination are correlated to durational variation by looking at the results of acoustic analysis.

28) Sheldon \& Strange (1982) also claims that the difficulty of perceiving the English liquids in consonant cluster is attributed to coarticulation effects caused when an English liquid is produced preceded by a stop consonant.

29) According to Borden et al. (1984), coarticulation results from the temporal overlap between the articulatory gestures of two sounds. That is, coarticulation may be generally defined as the overlapping of adjacent articulations or as two articulators moving at the same time for different phonemes. 
3.5 Total mean duration value of the inserted vowel in gem, $\mathrm{pl}$ and $\left.\mathrm{pn}^{30}\right)$

Now, let us compare the total mean duration values in gem, $\mathrm{pl}$, and pn in order to provide more comprehensive analysis. The following table shows the duration of vowel insertion with gemination [vll], phonological epenthesis [vl], and phonetic intrusion $[\mathrm{v}]$ in the production of onset clusters in ESL, MSL, and HSL 31$)$.

Table 7.Total mean duration value of gem[vll], pl[vl], and $\mathrm{pn}[\mathrm{v}]$

\begin{tabular}{|c|c|c|}
\hline $\begin{array}{c}\text { Total Mean } \\
\text { value(gem) }\end{array}$ & $\begin{array}{c}\text { Total Mean } \\
\text { value(pl) }\end{array}$ & $\begin{array}{c}\text { Total Mean } \\
\text { value(pn) }\end{array}$ \\
\hline $0.13(\mathrm{~s})$ & $0.11(\mathrm{~s})$ & $0.05(\mathrm{~s})$ \\
\hline
\end{tabular}

In the table above, we confirmed the duration of three types of vowel insertion patterns. The mean value of the duration of [vll] amounts to $0.13(\mathrm{~s})$, is considerably long (0.13(s)), compared with other insertion types. The mean value of the duration of [vl] is $0.11(\mathrm{~s})$. On the other hand, the total mean value of the duration of the inserted vowel in phonetic intrusion is significantly short $(0.05(\mathrm{~s}))$. Thus, we can say that the duration of [vll] is considerably longer than those of other types of vowel insertion patterns.

3.6 Age - dependence difference in terms of vowel insertion patterns

Now, let us look at age - dependence difference in terms of vowel insertion patterns in the following table. The following table shows the difference ratio of vowel insertion patterns according to age groups.

Table 8. Age - dependence difference in vowel insertion patterns

\begin{tabular}{|c|c|c|c|}
\hline $\begin{array}{c}\text { Age } \\
\text { group }\end{array}$ & $\begin{array}{c}\text { Vowel } \\
\text { insertion with } \\
\text { gemination }\end{array}$ & $\begin{array}{c}\text { Phonological } \\
\text { epenthesis }\end{array}$ & $\begin{array}{c}\text { Phonetic } \\
\text { intrusion }\end{array}$ \\
\hline ESL & $65.88 \%$ & $26.47 \%$ & $7.65 \%$ \\
\hline MSL & $54.49 \%$ & $41.92 \%$ & $3.59 \%$ \\
\hline HSL & $46.43 \%$ & $58.9 \%$ & $2.68 \%$ \\
\hline
\end{tabular}

30) Here, gem indicates vowel insertion with gemination, pl represents phonological epenthesis, and pn refers to phonetic intrusion.

31) ESL refers to elementary school learners, MSL indicates middle school learners, and HSL means high school learners.
As seen above, we can confirm that the ratio of vowel insertion with gemination and phonetic intrusion decreases as age group is older, while the ratio of phonological epenthesis increases as the age group is older, which is demonstrated in the table above. The result of the experiment is unexpected in that vowel insertion with gemination in ESL occurs more frequently than the other groups. In specific, based on the findings from the present acoustic analysis, we can see that both phonological process and phonetic factors were involved in vowel insertion patterns by Korean speakers. The statistic test as to the validity of these results will be discussed in the following section.

\subsection{The results of the statistic tests}

The following statistic test is designed to detect whether there are statistically significant differences based on the results of experiments conducted in the current study. That is, in order to see whether there is a difference in terms of vowel insertion between onset $\mathrm{C}+/ \mathrm{r} /$ and onset $\mathrm{C}+/ 1 /$, paired t-test was carried out.

Table 9. The results of paired t-test in $\mathrm{C}+/ \mathrm{r} /$ vs. $\mathrm{C}+/ \mathrm{l} /$ clusters

\begin{tabular}{|c|c|c|c|}
\hline Source & $\mathrm{t}$ & $\mathrm{df}$ & Sig.(2-tailed) \\
\hline Onset_C+/r/ - Onset_C+/1/ & 36.349 & 2 & .001 \\
\hline
\end{tabular}

The table above shows that the frequency of vowel insertion in $\mathrm{C}+/ \mathrm{r} /$ and $\mathrm{C}+/ \mathrm{l} /$ onset clusters is statistically significant. $(p<0.005)$. Thus, this result of paired t-test of the occurrence of vowel insertion in $\mathrm{C}+/ \mathrm{r} /$ vs. $\mathrm{C}+/ \mathrm{l} /$ clusters is an important clue to prove the validity of providing evidence based on L1 transfer rather than universal markedness.

Next, The following statistic test is designed to see whether there are statistically significant durational differences between vowel insertion patterns based on the results of experiments conducted in the current study. The following table shows the result of a mixed ANOVA as to duration according to vowel insertion types.

Table 10. A mixed ANOVA of duration

\begin{tabular}{|l|l|}
\hline Insertion_type & $\left.\mathrm{F}(4,2240)=5074.283, \mathrm{MSE}^{32}\right)=6.333$, \\
\hline Duration & $\mathrm{p}=.000 \quad(\mathrm{p}<.001)$ \\
\hline
\end{tabular}

As shown in the table above, the result of mixed ANOVA on the difference between duration and vowel insertion patterns

32) Here, MSE refers to mean square error. 
was considerably significant as we expected. Thus, this result can support the assumption that there was a significant effect in terms of duration and vowel insertion patterns.

As for frequencies of three kinds of vowel insertions, there was significant effect in the number of occurrence of vowel insertion with gemination and phonological epenthesis $(p<0.005)$. On the other hand, there was no significant effect in the number of occurrence of phonetic intrusion due to the low frequencies of phonetic intrusion according to the statistical tests that were applied.( $\mathrm{p}>.05)$.

In addition, as for frequencies of three kinds of vowel insertions, the distinction of insertion types (gem, pl, pn) by age groups is statistically significant only in elementary school $(p<0.05)$, not significant in middle and high school $(p>0.05)$.

To conclude, the validity of the classification of gem, $\mathrm{pl}$, and pn, with regard to duration and cluster types based on the results of statistics was proved. Thus, I can safely say that the distinction of vowel insertion patterns according to duration regarding $\mathrm{C}+/ \mathrm{r} /$ and $\mathrm{C}+/ 1 /$ clusters is statistically significant.

\section{Phonetic intrusion in the sequence of $\mathrm{C}+/ \mathbf{r} /$ clusters}

In the present study, phonetic intrusion is observed in $\mathrm{C}+/ \mathrm{r} /$ clusters much more than $\mathrm{C}+/ \mathrm{l} /$ clusters. That is, the ratio of phonetic intrusion in the $\mathrm{C}+/ \mathrm{r} /$ clusters is higher than that of $\mathrm{C}+/ \mathrm{l} /$ clusters $^{33}$ ). Let us first look at the following figure, and examine how phonetic intrusion takes place in the sequence of $\mathrm{C}+\mathrm{r} /$ clusters.

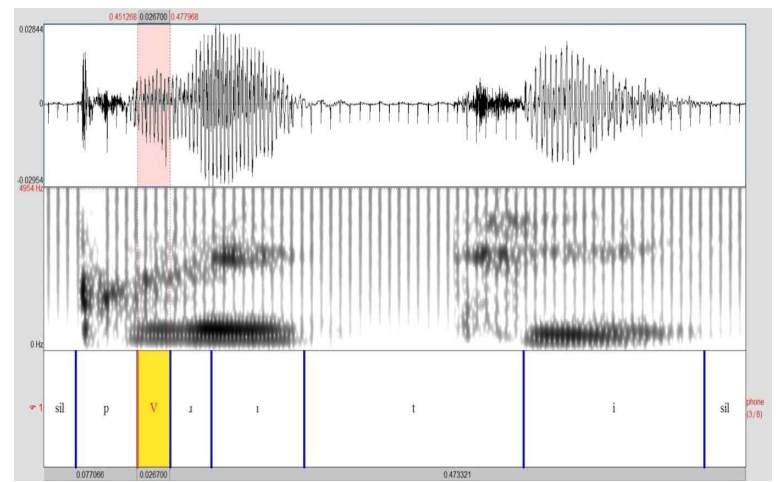

Figure 6. The spectrogram and waveform of onset_R_'pretty' produced by_HN (phonetic intrusion)

33) According to Yoo (2004), she claims that $/ \mathrm{br} /$ and $/ \mathrm{fl} /$ are the most problematic consonant onsets and $/ \mathrm{br} /$ is a clear case that shows interactions between markedness and transfer. Whereas, Jun (2003) contends that /1/ causes fewer problems, since $/ \mathrm{r} /$ is more marked than $/ 1 /$.
As is shown in the figure above, we can confirm that the duration of the inserted vowel in the $\mathrm{C}+/ \mathrm{r} /$ clusters is considerably short $(0.026(\mathrm{~s}))$, and that the formant structure is very unstable and unclear. Accordingly, we can see that the duration of inserted vowel of phonetic intrusion is very short in comparison with vowel insertion with gemination and phonological epenthesis. In this respect, we can conjecture that the inserted vowel in phonetic intrusion is similar to schwa in that the duration is considerably short and the formant values are extremely unstable.

As mentioned above, the most striking finding is that phonetic intrusion mostly occurs in $\mathrm{C}+\mathrm{r} / \mathrm{r}$ clusters. Specifically, the duration of the inserted vowel in words such as throw, dragon, friend, green is significantly short. In addition, formant values of the inserted vowel in these words vary. This is due to the fact that the vowel quality of the inserted vowel in phonetic intrusion is similar to schwa. Accordingly, we can say that the inserted vowel in phonetic intrusion is similar to schwa-like transition, and that phonetic intrusion mostly occurs in $\mathrm{C}+/ \mathrm{r} /$ clusters in the onset.

\section{Conclusion}

This study set out to investigate the vowel insertion patterns of English consonant clusters among Korean learners. The results of acoustic analysis revealed that Korean speakers use three types of vowel insertion patterns such as phonetic intrusion, phonological epenthesis, and vowel insertion with gemination. This indicates that vowel insertion patterns can be divided into three parts depending on the phonetic feature of the inserted vowel and $/ 1 /$ and $/ \mathrm{r} /$. Regarding $\mathrm{C}+/ \mathrm{r} /$ clusters, unlike $\mathrm{C}+/ \mathrm{l} /$ clusters, we observed that phonetic intrusion is more likely to occur due to the phonetic nature of the inserted vowel and $/ \mathrm{r} /$. On the other hand, it is observed that vowel insertion with gemination mainly occurs in $\mathrm{C}+/ \mathrm{l} /$ clusters.

Specifically, as for $\mathrm{C}+/ \mathrm{l} /$ clusters, I focused on the correlation between vowel insertion and duration of the inserted vowel and /1/ in conjunction with gestural coordination. As a result, the present experiment indicates that the coordination of articulators affects the duration of the inserted vowel and /1/ and duration correlates with vowel insertion patterns. In addition, based on the findings from the current experiment, I also showed age-dependence difference, which indicates that the ratio of vowel insertion with gemination and phonetic intrusion decreases as age group is older, while the ratio of phonological 
epenthesis increases as the age group is older.

Interestingly, the finding of acoustic analysis demonstrates that vowel insertion is more likely to occur when they produce $\mathrm{C}+/ \mathrm{l} / \mathrm{(71.73 \% )}$ than $\mathrm{C}+\mathrm{r} / \mathrm{clusters}(11.56 \%)$. That is, there occur asymmetries in the frequency of vowel insertion depending on liquid types of $\mathrm{C} 2$. Therefore, I can safely say that vowel insertion of Korean speakers' production in word-initial $\mathrm{C}+/ \mathrm{l} / \mathrm{and} \mathrm{C}+/ \mathrm{r} /$ clusters is affected by the following consonant $(\mathrm{C} 2)$ as well as the preceding consonant $(\mathrm{C} 1)$ in a cluster. The reason of this discrepancy in $\mathrm{C}+/ \mathrm{l} /$ and $\mathrm{C}+/ \mathrm{r} /$ clusters may be due to the difference of liquid types of $\mathrm{C} 2$ in a cluster related to duration of geminate [11] in Korean. Thus, this result provides a piece of evidence that duration of $/ 1 /$ is strongly involved in vowel insertion patterns. That is to say, the reason why the occurrence of the vowel insertion in $\mathrm{C}+/ \mathrm{l} /$ onset clusters is higher than $\mathrm{C}+/ \mathrm{r} /$ onset clusters may be attributed to L1 transfer since the sound structure of the /1/ in cluster position is more similar to that of the geminate [11] in Korean.

To conclude, this study provides evidence for L1 transfer, and the duration effect of $/ 1 /$ through three kinds of vowel insertion patterns in conjunction with gestural constraint.

\section{References}

Ahn, S. C. (1998). An Introduction to Korean Phonology. Seoul: Hanshin Publishing Co.

Ahn, S. C. \& Iverson, G. (2004). Dimensions in Korean laryngeal phonology. Journal of East Asian Linguistics 13.4, 343-379.

Ahn, S. C. (2008). On the ambivalent representation of the Korean liquid. Studies in phonetics, phonology and morphology 14.3, 389-409.

Ahn, S. C. (2009). On the evolution of the laryngeal contrasts in Korean. Studies in phonetics, phonology and morphology 15.3, 465-484.

Anderson, J. (1987). The markedness differential hypothesis and syllable structure difficulty. In Georgette loup, and Steven Weinberger (eds.). Interlanguage Phonology: The Acquisition of a Second Language Sound System, 279-291. New York: New bury House/Harper and Row.

Borden, G. J. \& Harris, K. S. (1984). Speech Science Primer: Physiology, Acoustics, and Perception of Speech. Baltimore: Williams and Wilkins.

Broselow, E. \& Finer, D. (1991). Parameter setting in second language phonology and syntax. Second Language Research 7.1, 35-59.
Broselow, E. \& Park, H. B. (1995). Mora conservation in second Language Prosody. In Archibald, John (eds) Phonological Acquisition and Phonological Theory, 151-168. Hillsdale: Erlbaum.

Browman, C. P. \& Goldstein, L. (1986). Towards an articulatory phonology. Phonology Yearbook 3, 219-252.

Browman, C. P. \& Goldstein, L. (1990). Tiers in articulatory phonology, with some implications for casual speech. In J. Kingston \& M. Beckman (Eds.), Papers in laboratory phonology I: Between the grammar and physis if speech, 341-376. New York: Cambridge University Press.

Browman, C. P. \& Goldstein, L. (1992a). Articulatory phonology: An overview. Phonetica 49, 155-180.

Browman, C. P. \& Goldstein, L. (1992b). "Targetless" schwa: an articulatory analysis. In G. J. Docherty \& D, R. Ladd (Eds.), Papers in laboratory Phonology: Gesture, Segment, Prosody. Cambridge: Cambridge University Press.

Carter, P. (2003). Extrinsic phonetic interpretation: spectral variation in English liquids. In Local, J., Richard Ogden \& Rosalind Temple (eds.), Phonetic Interpretation Papers in Laboratory Phonology $U$, 240. Cambridge: Cambridge University Press.

Catford, J. C. (1988). A Practical Introduction to Phonetics. Oxford: Oxford University Press.

Cho, M. H. \& Lee, S. S. (2005). Repair strategies of English biconsonantal coda clusters: an optimality-theoretic account in conjunction with P-Map. Studies in Phonetics, Phonology and Morphology 11.2, 367-390.

Chomsky, N. \& Halle, M. (1968). The Sound Pattern of English. New York: Harper \& Row.

Cote, M. H. (2000). Consonant cluster phonotactics: A perceptual approach. Ph. D dissertation. MIT.

Davis, S. \& Cho, M. H. (2004). English word final /s/ in Korean loanword phonology. Unpublished Ms. University of Indiana and Kyonggi University.

Eckman, F. R. (1991). The structural conformity hypothesis and the acquisition of consonantal clusters in the interlanguage of ESL learners. Studies in Second Language Acquisition 13, 23-41.

Eckman, F. R. (1977). Markedness and the contrastive analysis hypothesis. Language Learning 27, 315-330.

Eckman, F. R. \& Iverson, G. (1993). Sonority and markedness among onset clusters in the interlanguage of ESL learners. Second Language Research 9.3, 234-252.

Fan, Y. (2004). Modification of English complex codas by 
Mandarin Speakers: An Optimality Theory and P-map account. Ms. Michigan State University.

Flege, J. E. (1987). The production of "new" and "similar" in a foreign language: Evidence for the effect of equivalence classification. Journal of Phonetics 15, 47-65.

Flege, J. E. (1995). Second language speech learning: Theory, Findings and Problems. In W. Strange (Ed.), Speech perception and linguistic experience: Issues in cross language research 233-272. Timonium, MD: York Press.

Flege, J. et al. (1995). Effects of age of second language learning on the production of English consonants. Speech Communication 16, 1-26.

Hayes, B. (1986). Inalterability in CV phonology. Language 62: 321-351.

Hayes, B. (1989). Compensatory Lengthening in Moraic Phonology. Linguistic Inquiry 20, 253-306.

Hancin-Bhatt, B. \& Bhatt, R. (1997). Optimal L2 Syllables: Interactions of Transfer and Developmental Effects. Studies in Second Language Acquisition, 19, 331-378.

Iverson, G. \& Sohn, H. M. (1994). Liquid Representation. In Y. Kim-Renaud (Ed.). Theoretical Issues in Korean Linguistics, 77-100. Center for the Study of Language and Information.

Jun, E. (2003). The Perception of English /1/ and /r/ by Korean speakers. Studies in Phonetics, Phonology and Morphology . 9.2, 471-484.

Jun, E. (2005). A comparative study on acquisition of English liquids. The journal of humanities Vol. 5, No. 1, 129-148.

Kager, R. (1999). Optimality Theory. Cambridge University Press.

Kang, Y. J. (2003). Perceptual similarity in loanword adaptation: English postvocalic word-final stops in Korean. Phonology 20, 219-273.

Kenstowicz, M. (2004). The phonetics and phonology of Korean loanword adaptation. Ms. MIT.

Kim, H. Y. (2005). Consonant clusters and syllable structure in English: an experimental approach. Doctoral Dissertation, Seoul National University.

Kwon, B. Y. (2005). The patterns of vowel insertion in IL phonology: The P-map account. Studies in Phonetics, Phonology and Morphology 11.2, 21-49.

Lado, R. (1957). Linguistics Across Cultures: Applied linguistics for language teachers. Ann Arber, Machigan: University of Michigan Press.

Lee, B. R. \& Lee, S. H. (2003). Korean Learners' Perception and Production of English Liquids. Malsori 52, 62-83.

Lee, J. H. (2005). Liquid gemination, variation, and loanwords in moraic phonology. Studies in Phonetics, Phonology and Morphology 11.1, 125-136.

Lee, S. S. \& Cho, M. H. (2002). An Optimality-theoretic Approach to Chain Shifts in Second Language Acquisition. English Language and Literature Vol. 48, No. 4, 933-953.

Lee, S. S. \& Cho, M. H. (2002). Sound replacement in the acquisition of English consonant clusters: a constraint-based approach. Studies in Phonology and Morphology. 8.2, 255-271.

Lee, S. S., Joh, J. S. \& Cho, M. H. (2002). Acquisition of English Consonant Clusters Among Korean EFL Leaners. Korean Journal of Linguistics 27-3, 439-472.

Lee, S. S. \& Cho, M. H. (2005). A Unified Approach to Perception and Production of English Consonant Clusters. Proceedings of The 26th ELSOK conference. The English Linguistic Society of Korea.

Levin, J. (1987). Between epenthetic and excrescent vowels. WCCFL: Proceedings of the West Coast Conference on Formal Linguistics 6, 187-201.

Major, R. (1994). Chronological and Stylistic Aspects of Second Language Acquisition of Consonant Clusters. Language Learning 44, 655-680.

Oh, M. R. (2005). Phonetic and spelling information in loan adaption. Korean Journal of Linguistics 30, 347-368.

Oh, M. R. \& Kim, H. S. (2006). A phonetic duration-based analysis of vowel epenthesis: English postvocalic word-final stops. Studies in Phonetics, Phonology and Morphology 12. 2, 307-320.

Park, H. B. (1992). External Evidence for Representations, Rules, and Constraints in Korean and Japanese. Ph. D dissertation. State University of New York.

Prince, A. \& Smolensky, P. (1993). Optimality Theory: Constraint Interaction in Generative Grammar. Ms. Rutgers University.

Sato, C. J. (1984). Phonological processes in second language acquisition: Another look at interlanguage syllable structure. Language learning 34, 43-57.

Sheldon, A. \& Strange, W. (1982). The acquisition of /r/ and /1/ by Japanese learners of English: Evidence that speech production can precede speech perception. Applied Psycholinguistics 3, 243-261.

Shibuya, Y. (2005). Production and perception of consonant clusters in the L2 phonology of Japanese learners of English. $\mathrm{Ph}$. D dissertation. Georgetown University.

Steriade, D. (2001a). Directional asymmetries in place assimilation: A perceptual account. The role of speech perception in phonology, ed. by E. Hume and K. Johnson. San 
Diego: Academic Press.

Steriade, D. (2001b). The phonology of perceptibility effects: the P-map and its consequences for constraint organization. Ms. UCLA.

Yoo, H. B. (1996). Markedness and Faitfulness Constraints in the Acquisition of Korean Liquids. Korean Journal of Linguistics 21-4, 1085-1104.

Yoo, H. B. (2004). A longitudinal study of consonant cluster acquisition. Studies in Phonetics, Phonology and Morphology $10.3,481-503$.

Yoo, H. B. (2009). Representation of English loanwords in Korean orthography: gemination and vowel insertion. Studies in Phonetics, Phonology and Morphology 15.2, 301-324.

\author{
- Seo-Yoon Kang \\ Department of English Language and Literature \\ Kyung Hee University \\ Hoegi-dong, Dongdaemun-gu \\ Seoul 130-701, Korea \\ Mobile: 010-8580-2546 \\ Email: sjkang620@naver.com \\ 관심분야: 음성학, 음운론 \\ 현재 영어영문학과 대학원 박사과정 수료
}

